
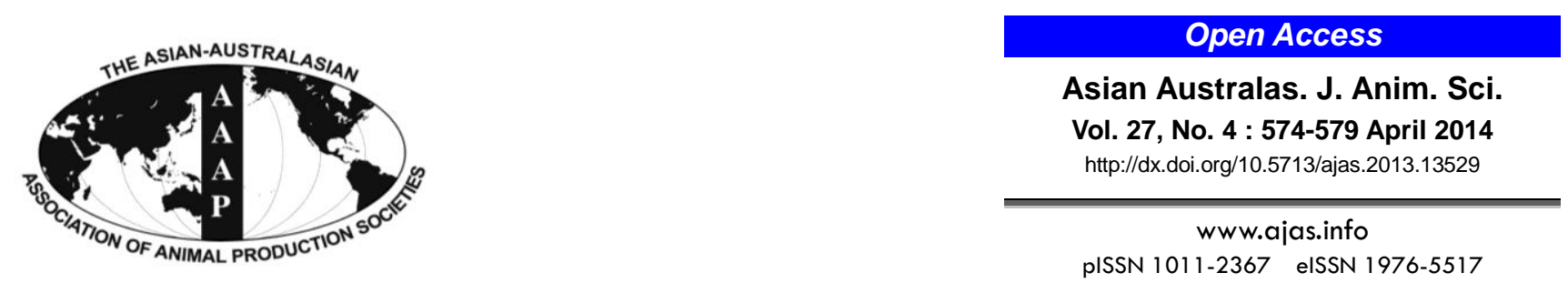

\title{
Expression, Purification, and Characteristic of Tibetan Sheep Breast Lysozyme Using Pichia pastoris Expression System
}

\author{
Jianbo $\mathrm{Li}^{1,2}$, Mingfeng Jiang ${ }^{1,2}$, and Yong Wang ${ }^{1, *}$ \\ ${ }^{1}$ Key Laboratory of Sichuan Province for Qinghai-Tibetan Plateau Animal Genetic Resource Reservation and \\ Exploitation, Chengdu 610041, China
}

\begin{abstract}
A lysozyme gene from breast of Tibetan sheep was successfully expressed by secretion using a-factor signal sequence in the methylotrophic yeast, Pichia pastoris GS115. An expression yield and specific activity greater than $500 \mathrm{mg} / \mathrm{L}$ and 4,000 U/mg was obtained. Results at optimal pH and temperature showed recombinant lysozyme has higher lytic activity at $\mathrm{pH} 6.5$ and $45^{\circ} \mathrm{C}$. This study demonstrates the successful expression of recombinant lysozyme using the eukaryotic host organism P. pastoris paving the way for protein engineering. Additionally, this study shows the feasibility of subsequent industrial manufacture of the enzyme with this expression system together with a high purity scheme for easy high-yield purification. (Key Words: Clone, Lysozyme, Pichia pastoris, Purification, Secretory Expression, Tibetan Sheep)
\end{abstract}

\section{INTRODUCTION}

Lysozyme (LZM, EC 3.2.1.17), a crucial enzyme in both innate immunity and digestion (Prager and Joliès, 1995; Leippe, 1999), can hydrolyze $\beta$-1,4-linkages between $\mathrm{N}$-acetyl-D-glucosamine and $\mathrm{N}$-acetylmuramic acid residues of the peptidoglycan layer of bacterial cell walls (Salton and Ghuysen, 1959). LZM has been found existing in various species where reports shown that LZM has antibacterial, anti-viral and anti-tumor activities (Ferrari et al., 1959; Hughey and Johnson, 1987; Sava et al., 1989). Futhermore, changes on LZM concentration in serum or urine can be used as a diagnostic marker for certain diseases (Peeters et al., 1978). Thus, LZM is under study as a potentially useful material for industrial use such as in medicinal feed, baby formula, and various food products (Yang et al., 2011).

The $P$. pastoris expression system has several

\footnotetext{
* Corresponding Author: Yong Wang. Tel: +86-28-85522060, Fax: +86-28-85522060, E-mail: wangyong010101@ swun.cn ${ }^{2}$ College of Life Science and Technology, Southwest University for Nationalities, Chengdu 610041, China.

Submitted Aug. 23, 2013; Accepted Nov. 17, 2013; Revised Nov. 30, 2013
}

advantages over other eukaryotic and prokaryotic expression systems such as the ease of manipulation, diverse post-translational modifications i.e. polypeptide folding, acylation, glycosylation, methylation, proteolytic adjustment, rapid growth rate and high expression levels ( $\mathrm{Li}$ et al., 2007).

Tibetan sheep LZM is a C-type LZM, a single polypeptide composed of 130 amino acid residues. LZM widely existed in Tibetan sheep tissues or body fluids and also plays an important role as an anti-inflammatory factor (Ogundele, 1998). LZM, in sheep milk, can help prevent disease infection in infants and improve non-special immunity. However, until now, research on Tibetan sheep breast LZM (SLZ) has not been reported. Thus, we cloned the $S L Z$ gene and successfully expressed it in P. pastoris GS115 using the expression vector pPICZ $\alpha$ A at first time. We also optimized a method for purifying recombinant SLZ (rSLZ) from yeast culture for potential large-scale production in the future.

\section{MATERIALS AND METHODS}

\section{Materials}

Tissue samples of Tibetan sheep breast were collected

Copyright @ 2014 by Asian-Australasian Journal of Animal Sciences This is an open-access article distributed under the terms of the Creative Commons Attribution Non-Commercial License (http://creativecommons.org/licenses/by-nc/3.0/) which permits unrestricted non-commercial use, distribution, and reproduction in any medium, provided the original work is properly cited. 
from a 4-yr-old healthy female Tibetan sheep from Ruoergai county of Sichuan province. E. coli DH5 $\alpha$ (Invitrogen, Carlsbad, Calif., USA) was used for subcloning and yeast vector amplification. $P$. pastoris GS115 (Invitrogen) was used as the host for rSLZ. All reagents were from commercial sources.

\section{Growth media and conditions}

Yeast extract peptone dextrose medium (YPD) contains $1 \%$ yeast extract, $2 \%$ peptone, $2 \%$ dextrose and $2 \%$ agar. Buffered glycerol-complex medium (BMGY) contains $1 \%$ yeast extract, $1 \%$ glycerol, $2 \%$ peptone, $\left(4 \times 10^{-5}\right) \%$ biotin, $1.34 \%$ yeast nitrogen base and was supplemented with 100 mmol/L potassium phosphate ( $\mathrm{pH}$ 6.0). Buffered methanolcomplex medium (BMMY) was prepared in accordance with BMGY but containing $0.5 \%$ methanol instead of $1 \%$ glycerol.

\section{Screening and amplification of SLZ cDNA}

Total RNA was extracted from Tibetan sheep breast using Trizol RNA extraction kit (life technologies, USA). The oligonucleotides with sequences of 5'-TCTCTCGAGA AAAGAGAGGCTGAAGCTAAGGTCTTTGAGAGATGT GA-3' and 5'- CTGTCTAGATCACACTCCACAACCC TGAATG-3' were designed based on the open reading frame of the SLZ (GenBank accession No. KF871070) without its signal sequence and used as specific primers for PCR reactions. Restriction sites at the 5' ends of the primers for XhoI and XbaI (underlined) were incorporated to facilitate subcloning of the PCR product. Amplification was performed using pfu DNA polymerase by PCR reaction for 30 cycles (denaturation: $94^{\circ} \mathrm{C}$ for $30 \mathrm{~s}$; annealing: $54^{\circ} \mathrm{C}$ for $30 \mathrm{~s}$; and extension: $72^{\circ} \mathrm{C}$ for $30 \mathrm{~s}$ ). After, the inserted cDNA fragment was sequenced.

\section{Construction of expression plasmids and transformation of Pichia pastoris GS115}

The PCR product of the specific primer was purified and cloned into pMD19-T.The recombinant plasmid was digested with $X b a \mathrm{I}$ and $\mathrm{XhoI}$ and the small fragment was separated and ligated into the expression vector pPICZ $\alpha$ A. This recombinant plasmid was named pPICZ $\alpha \mathrm{A}-\mathrm{SLZ}$ and finally confirmed by sequencing. The plasmid pPICZ $\alpha \mathrm{A}-$ SLZ was linearized with $S a c I$ and transformed into $P$. pastoris GS115 using lithium chloride transformation method according to the manufacturer's protocol (Invitrogen, Pichia Expression Kit). The transformants were cultivated at $30^{\circ} \mathrm{C}$ for 1 to $4 \mathrm{~h}$ and then spread over YPDZ (YPD medium plus $2.5 \times 10^{-3} \%$ Zeocin) plates cultured at $30^{\circ} \mathrm{C}$ for 2 to $3 \mathrm{~d}$. An enhanced Zeocin selection with a 5 to 20 fold concentration (12.5 to $50 \times 10^{-3} \%$ Zeocin) of Zeocin was performed to screen multicopy recombinant colonies. One of transfortmants with a high Zeocin resistance was selected for expression.

\section{Cultivation of Pichia pastoris GS115 and expression of pPICZ $\alpha$ A-SLZ}

The transformant was inoculated into $10 \mathrm{~mL}$ of BMGY medium and cultured at $28^{\circ} \mathrm{C}$ on a rotary shaker at $200 \mathrm{rpm}$ for 2 days until OD600 nm value was 2-6. The yeast cells were harvested and resuspended in $20 \mathrm{~mL}$ of BMMY medium at an OD600 $\mathrm{nm}$ value of $1\left(0.5 \times 10^{8}\right.$ cells $\left./ \mathrm{mL}\right)$. The culture was grown at $28^{\circ} \mathrm{C}$ with constant shaking on a rotary shaker at $220 \mathrm{rpm}$ for $168 \mathrm{~h}$. The culture was supplemented every $24 \mathrm{~h}$ with $0.5 \%(\mathrm{v} / \mathrm{v})$ methanol to maintain the induction of transformant expression.

\section{Purification of rSLZ from Pichia pastoris culture media}

The culture was centrifuged for $20 \mathrm{~min}$ at $5,000 \mathrm{~g}$ at $4{ }^{\circ} \mathrm{C}$. The supernatant was collected and ammonium sulfate was added to the crude extract to $65 \%$ saturation. The protein was precipitated and dissolved in PBS (phosphate buffer solution, $\mathrm{pH}$ 6.0) buffer and finally dialyzed in a regenerated cellulose membrane for $36 \mathrm{~h}$ and replaced dialyzate every $12 \mathrm{~h}$. The solution was loaded onto a DEAE-Sepharose Fast Flow column (GE Healthcare) equilibrated with Tris buffer $(\mathrm{pH} 9.0$, ionic strength $=10$ $\mathrm{mM}, 50 \mathrm{mM}$ Tris and $4.3 \mathrm{mM} \mathrm{NaCl}$ ) and eluted with a linear gradient of Tris buffer $(\mathrm{pH} 9.0$, ionic strength $=10$ $\mathrm{mM}, 50 \mathrm{mM}$ Tris and $4.3 \mathrm{mM} \mathrm{NaCl}),-1 \mathrm{M} \mathrm{NaCl}$. Afterwards, the main peak was determined. Fractions with high rSLZ activity were pooled and stored at $-20^{\circ} \mathrm{C}$. After freeze-drying (Telstar*LyoQuest, Spain), rSLZ was purified by gel-filtration on a Sephadex G-75 (Pharmacia) HR column on a BioLogic LP chromatography system (BioRAD, USA). The flow rate was $0.2 \mathrm{~mL} / \mathrm{min}$, and the column was equilibrated and eluted using Tris buffer $(\mathrm{pH}$ 9.0 , ionic strength $=10 \mathrm{mM}, 50 \mathrm{mM}$ Tris and $4.3 \mathrm{mM}$ $\mathrm{NaCl}$ ). The active fractions were pooled, desalinated and referred to as the purified enzyme preparation. The rSLZ fraction was identified by SDS-PAGE.

\section{Enzyme assay and molecular properties}

rSLZ activity was measured using Micrococcus lysodeikticus as substrate at a concentration of $0.25 \mathrm{mg} / \mathrm{mL}$ and recording the change in percent transmittance at 450 $\mathrm{nm}$ with time in a double beam UV-visible light spectrophotometer (Parry et al., 1965). One unit of rSLZ activity was defined as a $0.1 \%$ change in transmittance per minute. The protein concentration was determined by the Bradford method with bovine serum albumin as the standard (Bradford, 1976). SDS-PAGE was performed with $15 \%(\mathrm{v} / \mathrm{v})$ separating gel and 5\% (v/v) stacking gel. Protein 
bands were visualized using Coomassie blue staining method.

\section{RESULTS}

\section{Cloning of SLZ cDNA}

The DNA fragment encoding LZM was amplified by PCR reaction. From the data shown (Figure 1), a 429 bp sequence was obtained, which is completely consistent with the expected result, and then the sequence was purified and inserted into a pMD19-T vector. The recombinant plasmid was extracted and digested by $\mathrm{XbaI}$ and $\mathrm{XhoI}$, the result revealed that restriction enzyme digestion produced a 417 bp length DNA fragment (Figure 1). Finally the fragment was linked into pPICZ $\alpha$ A for extracellular expressions.

\section{Expression of rSLZ in Pichia pastoris}

As a basis for functional and structural studies, the SLZ cDNA was successfully expressed in $P$. pastoris under the control of the AOX1 promoter with the a-factor signal sequence for secretion. The cell density and activity of rSLZ increased until $144 \mathrm{~h}$, where it proceeded at a constant value $\left(14 \times 10^{8}\right.$ cells $/ \mathrm{mL}$ and $\left.1,800 \mathrm{U} / \mathrm{mL}\right)$.

\section{Purification of rSLZ}

rSLZ was purified to homogeneity from culture

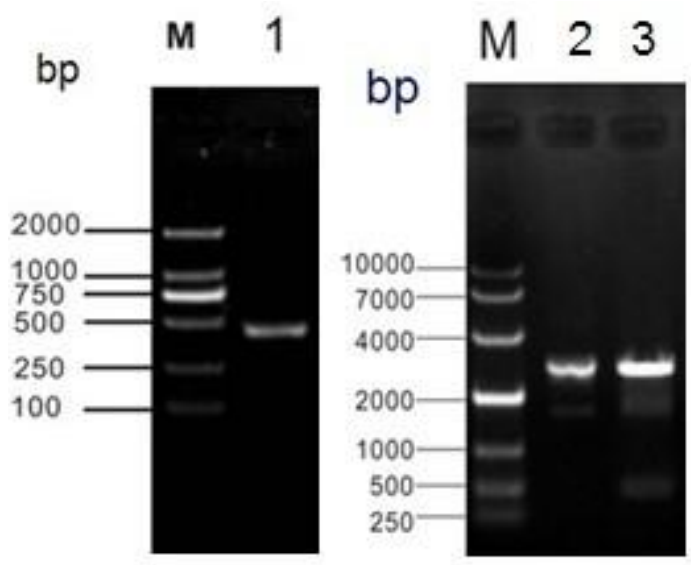

Figure 1. Agarose gel electrophoresis of PCR product and recombinant plasmid digested with XhoI and XbaI. Lane $\mathrm{M}=$ DNA marker; lane $1=$ PCR product; lane $2=$ recombinant plasmid; lane $3=$ recombinant plasmid digested with $X h o \mathrm{I}$ and XbaI. supernatant after $168 \mathrm{~h}$ of induction and it was purified by a two-step chromatographic procedure as outlined in Table 1. Anion exchange chromatography was followed by a gelfiltration chromatography step resulting in three fractions containing active rSLZ. Fractions were pooled and loaded on a Sephadex G-75 HR column where a homogenous enzyme preparation as judged by SDS-PAGE (Figure 2). After induction of $168 \mathrm{~h}$, concentration of rSLZ exceeded $500 \mathrm{mg} / \mathrm{L}$. Finally, 109\% of the initial activity was found in this enzyme preparation with a specific activity of 4,000 $\mathrm{U} / \mathrm{mg}$ representing a 10.2-fold purification from culture supernatant (Table 1). Recombinant protein from this pool was used for further analyses.

\section{Molecular properties}

The molecular mass of rSLZ expressed in $P$. pastoris GS115 was corresponded very well to the theoretical molecular mass of $14.5 \mathrm{kDa}$ based on the cDNA sequence of SLZ (Figure 2).

The optimal $\mathrm{pH}$ of the purified rSLZ varied with salt concentration (Figure 3 ). The highest activity of rSLZ was at $\mathrm{pH} 8$ when the salt concentration of the buffer was 0.01 $\mathrm{M}$; the highest activity of rSLZ was at $\mathrm{pH} 7$ when the salt concentration was $0.05 \mathrm{M}$ of the buffer; the highest activities of rSLZ were at $\mathrm{pH} 6$ and 5 when the salt concentrations of the buffers were 0.1 and $0.2 \mathrm{M}$, respectively. When using a buffer with a salt concentration of $0.01 \mathrm{M}$, rSLZ tested have a broader region of optimum

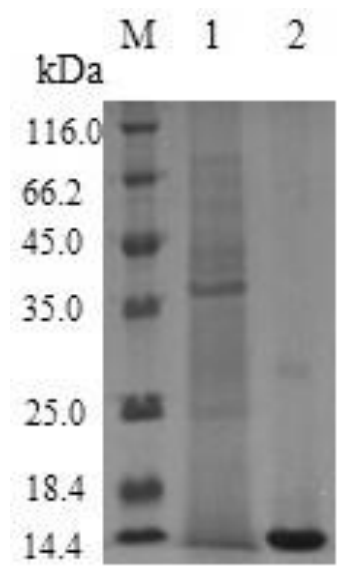

Figure 2. SDS-PAGE analysis of rSLZ purified from yeast culture. Lane $\mathrm{M}=$ protein molecular mass marker; lane $1=$ culture supernatant; lane 2 = purified rSLZ.

Table 1. Purification of rSLZ from yeast culture

\begin{tabular}{lcccccc}
\hline & $\begin{array}{c}\text { Total activity } \\
(\mathrm{U})\end{array}$ & $\begin{array}{c}\text { Total protein } \\
(\mathrm{mg})\end{array}$ & $\begin{array}{c}\text { Volume } \\
(\mathrm{mL})\end{array}$ & $\begin{array}{c}\text { Specific activity } \\
(\mathrm{U} / \mathrm{mg})\end{array}$ & $\begin{array}{c}\text { Purification } \\
(-\mathrm{fold})\end{array}$ & $\begin{array}{c}\text { Activity yield } \\
(\%)\end{array}$ \\
\hline Culture supernatant & 5,500 & 14 & 3 & 393 & 1.0 & 100 \\
DEAE Sepharose FF pool & 5,100 & 1.6 & 12 & 3,188 & 8.1 & 92.7 \\
Sephadex G-75 & $6,000^{\mathrm{a}}$ & 1.5 & 4 & 4,000 & 10.2 & $109^{\mathrm{a}}$ \\
\hline
\end{tabular}

${ }^{a}$ rSLZ activity is higher after desalinated.

${ }^{\mathrm{b}}$ Determination of molecular properties was done with protein from this fraction. 


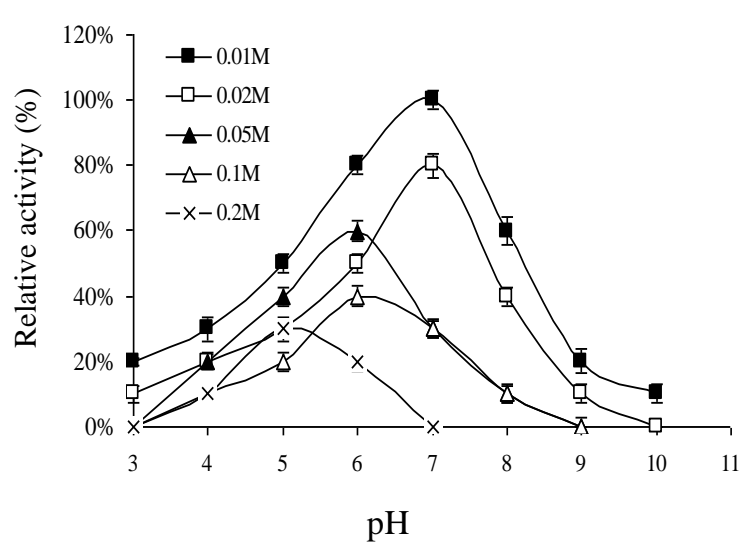

Figure 3. Dependence of activities of rSLZ on $\mathrm{pH}$ and ionic strength. The rSLZ activity assay was measured in different $\mathrm{pH}$ (3 to 10$)$ buffer with different salt concentration $(0.01 \mathrm{M}$ to $0.2 \mathrm{M})$, with Micrococcus lysodeikticus as substrate. The lytic activity was measured in phosphate buffer of $\mathrm{pH} \mathrm{3}$, sodium acetate buffers of $\mathrm{pH} 4$ to 5 , potassium dihydrogen phosphate buffer of $\mathrm{pH} 6$, MOPS buffers of $\mathrm{pH} 7$ to 8 , Tris buffer of $\mathrm{pH} 9$, and carbonate bicarbonate buffer of $\mathrm{pH} 10$. The experiment for each group was done in duplicates and the error was always below $5 \%$.

activity extending from $\mathrm{pH} 4$ to 9 than salt concentrations of buffer from $0.1 \mathrm{M}$ to $0.2 \mathrm{M}$, and the activity of rSLZ declined sharply at extreme $\mathrm{pH}$ values in ionic-strength buffers. We also found that the lytic activities of the rSLZ varied with $\mathrm{pH}$. The optimal $\mathrm{pH}$ assay revealed that $\mathrm{rSLZ}$ had a high activity at an acid $\mathrm{pH}$ and an alkaline $\mathrm{pH}(\mathrm{pH} 4$ to 8) (Figure 4).

The optimal temperature of the rSLZ was $45^{\circ} \mathrm{C}$ (Figure $5)$. The relative activity of $\mathrm{rSLZ}$ was compared under three different heating conditions $\left(50^{\circ} \mathrm{C}, 60^{\circ} \mathrm{C}\right.$, and $\left.70^{\circ} \mathrm{C}\right)$ after incubation for different times to reveal its thermostability (Figure 6). rSLZ maintained nearly $90 \%$ of its activity at $50^{\circ} \mathrm{C}$ after $40-\mathrm{min}$ incubation. The relative lytic activity of rSLZ decreased when incubated at $60^{\circ} \mathrm{C}$ or $70^{\circ} \mathrm{C}$ within 40

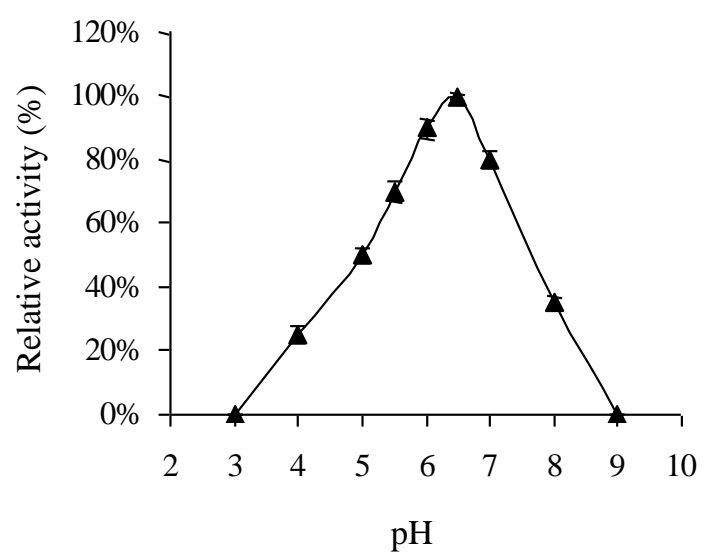

Figure 4. Dependence of lytic activity on $\mathrm{pH}$ for rSLZ. The rSLZ activity assay was measured at an ionic strength of 0.133 with Micrococcus lysodeikticus as substrate. The experiment for each group was done in duplicates and the error was always below $5 \%$.

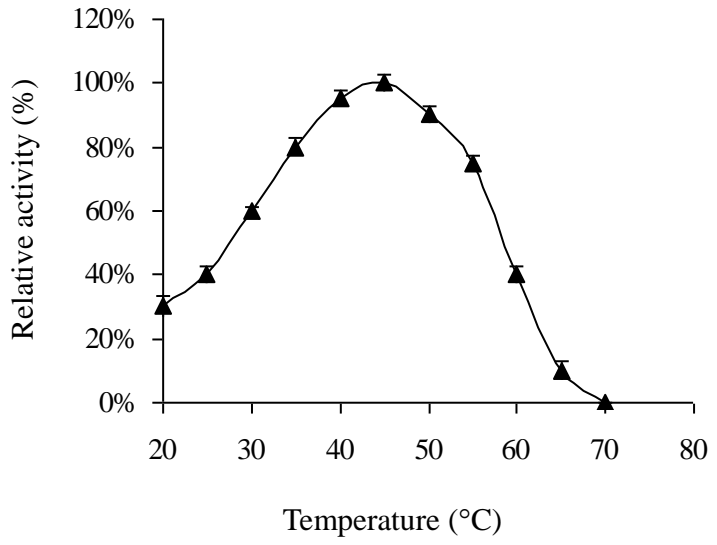

Figure 5. Dependence of lytic activity on temperature for rSLZ. The rSLZ activity assay was measured against Micrococcus lysodeikticus in $66 \mathrm{mM}$ potassium phosphate buffer, $\mathrm{pH} 6.24$, at different temperature $\left(20^{\circ} \mathrm{C}\right.$ to $\left.70^{\circ} \mathrm{C}\right)$ after incubation for $30 \mathrm{~min}$. Recombinant SLZ activity measured at $45^{\circ} \mathrm{C}$ represented $100 \%$ activity. The experiment for each group was done in duplicates and the error was always below 5\%.

min. After $10-\min$ incubation at $70^{\circ} \mathrm{C}$, the lytic activity was nearly $50 \%$ lower than that at $50^{\circ} \mathrm{C}$, and lytic activity was very low after a 30 -min treatment.

\section{DISCUSSION}

Production of SLZ in its natural source, Tibetan sheep, is extremely tedious and time consuming to be performed on high yields (Digan et al., 1989). The final yield and activity could be increased remarkablely with $P$. pastoris as expression host compared to native sheep milk. The first characterization and cDNA cloning of SLZ was reported by Irwin and Wilson (1990). Our work is the first to report the heterologous expression of rSLZ in P.pastoris and

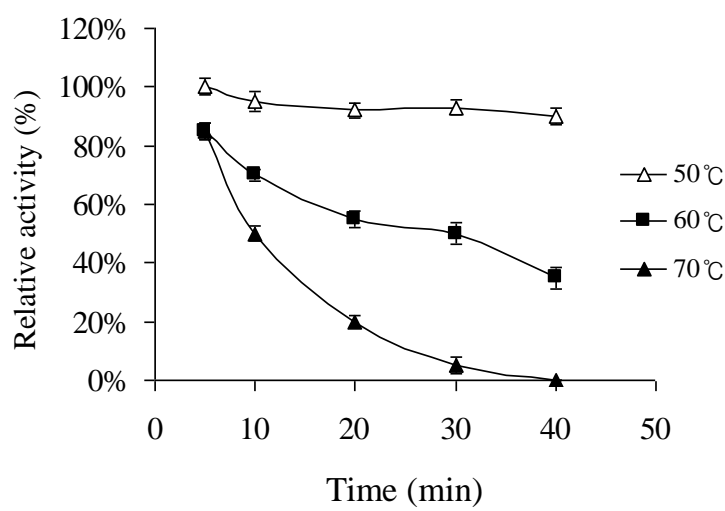

Figure 6. Thermostability of purified rSLZ at $50^{\circ} \mathrm{C}, 60^{\circ} \mathrm{C}$, and $70^{\circ} \mathrm{C}$. The rSLZ activity assay was measured against Micrococcus lysodeikticus in $66 \mathrm{mM}$ potassium phosphate buffer, $\mathrm{pH} 6.24$, at $25^{\circ} \mathrm{C}$ after incubation for different times at $50^{\circ} \mathrm{C}, 60^{\circ} \mathrm{C}$, and $70^{\circ} \mathrm{C}$. The experiment for each group was done in duplicates and the error was always below $5 \%$. 
additionally, the first to purify rSLZ by an experimental design protocol. The purification protocol with experimental design is a very useful tool to gain high yield and high levels of enzyme activity.

To extract rSLZ of high purity, we established a twostep chromatographic procedure for the purification of rSLZ from yeast culture. This purification procedure provides a new, high efficiency method for the extraction of high purity rSLZ from culture supernate. Using affinity chromatography to separate LZM can manufacture a high recovery and concentration (Vasstrand and Jensen, 1980). However, the coupling procedure used in affinity chromatography is complex and time consuming. Thus, this method has limited the possibility on an industrial scale. Ion-exchange chromatography has several advantages over affinity chromatography and it used to be as a common method in other expression systems for the purification of LZM (Iwata et al., 2004; Wilken and Nikolov, 2006). We selected Tris buffer for purification, and we optimized the $\mathrm{pH}$ and salt concentration. The best elution condition was with a buffer of $0.25 \mathrm{M}$ sodium chloride and $50 \mathrm{mM}$ Tris buffer at a $\mathrm{pH}$ of 9.0. Gel-filtration chromatography is a popular and versatile method that pursued the effective separation of proteins and high yield (Ó'Fágáin et al., 2011). In order to obtain high purity rSLZ and apply in possible subsequent industrial manufacture, gel-filtration chromatography was selected for the last step to purify rSLZ.

The optimal $\mathrm{pH}$ of the purified rSLZ varied with salt concentration in this study. For example, when the ionic strength gone up from $0.01 \mathrm{M}$ to $0.2 \mathrm{M}$, the lytic activities gone down by a factor of 3 (at the optimal $\mathrm{pH}$ ) just as has been reported before for oyster LZM (Xue et al., 2004) and hen egg white LZM (Davies et al., 1969). When the ionic strength declined to $0.01 \mathrm{M}, \mathrm{rSLZ}$ exhibited a remarkable increase in activity for optimal $\mathrm{pH}$, a similar phenomenon was observed with bird and human LZMs (Saint-Blancard et al., 1970; Maurel and Douzou, 1976). We also found that the lytic activities of the rSLZ varied with $\mathrm{pH}$. This phenomenon might be cause by the different solutions change the negative charge of the cell wall and the positive charge at the surface of the LZM, which reacts with rSLZ (Muraki et al., 1988; Kirby, 2001). The optimal pH assay of the purified rSLZ revealed that rSLZ had a high activity at an acid $\mathrm{pH}$ and an alkaline $\mathrm{pH}(\mathrm{pH} 4$ to 8). The $\mathrm{pH}$ of sheep milk is around 6.5-6.8 (Raynal-Ljutovac et al., 2008), which is optimal for the lytic activity of rSLZ. We infer that rSLZ will prolong the shelf-life of Tibetan sheep milk, and we are currently studying this possibility.

The optimal temperature and thermostability of the rSLZ were assayed because storage of rSLZ is an important consideration for commercial production. The US Food and
Drug Administration requires that Grade A pasteurized milk undergoes a minimum heating $72^{\circ} \mathrm{C}$ for $15 \mathrm{~s}$ (Ranieri et al., 2009). For rSLZ to be processed into production, about $90 \%$ of the enzyme activity remained. We conclude that post-processing procedures will have fewer effects on rSLZ activity.

The specific activity of rSLZ was 4,000 U/mg, which was lower than egg white LZM (Su and Chiang, 2006). However, the expression yield of rSLZ exceed $500 \mathrm{mg} / \mathrm{L}$ which could supplement the lower specific activity and if rSLZ use as a industrial material in the future that will have no toxin and no residue for human and animals due to its animal source.

In conclusion, we successfully cloned $S L Z$ gene that expressed in $P$. pastoris GS115 using pPICZ $\alpha \mathrm{A}$ as expression vector and finally obtained the purified rSLZ. In addition, this study could provide an inexpensive and industrial-scale method for the extraction of high purity rSLZ. Futhermore, we have shown that the enzymatic properties and physicochemical characteristics of rSLZ.

\section{ACKNOWLEDGEMENTS}

This research was supported by the Key Projects in the National Science and Technology Pillar Program during the Twelfth Five-Year Plan Period (No. 2012BAD13B06), the Key Demonstration Project of Science and Technology Innovation Industrial Chain in Sichuan province (No. 2011NZ0003), the Fundamental Research Funds for the Central Universities (No. 12ZYXS73).

\section{REFERENCES}

Bradford, M. M. 1976. A rapid and sensitive method for the quantitation of microgram quantities of protein utilizing the principle of protein-dye binding. Anal. Biochem. 72:248-254.

Davies, R. C., A. Neuberger, and B. M. Wilson. 1969. The dependence of lysozyme activity on $\mathrm{pH}$ and ionic strength. Biochem. Biophy. Acta Enzymol. 178:294-305.

Digan, M. E., S. V. Lair, R. A. Brierley, R. S. Siegel, M. E. Williams, S. B. Ellis, P. A. Kellaris, S. A. Provow, W. S. Craig G. Veliçelebi, M. M. Harpold, and G. P. Thill. 1989. Continuous production of a novel lysozyme via secretion from the yeast, Pichia pastoris. Nat. Biotechnol. 7:160-164.

Ferrari, R., C. Callerio, and G. Podio. 1959. Antiviral activity of lysozyme. Nature (Paris) 183:548.

Hughey, V. L. and E. A. Johnson. 1987. Antimicrobial activity of lysozyme against bacteria involved in food spoilage and foodborne disease. Appl. Environ. Microbiol. 53:2165-2170.

Irwin, D. M. and A. C. Wilson. 1990. Concerted evolution of ruminant stomach lysozymes. Characterization of lysozyme cDNA clones from sheep and deer. J. Biol. Chem. 265:49444952.

Iwata, T., R. Tanaka, M. Suetsugu, M. Ishibashi, H. Tokunaga, M. 
Kikuchi, and M. Tokunaga. 2004. Efficient secretion of human lysozyme from the yeast, Kluyveromyces lactis. Biotechnol. Lett. 26:1803-1808.

Kirby, A. J. 2001. The lysozyme mechanism sorted - after 50 years. Nat. Struct. Biol. 8:737-739.

Leippe, M. 1999. Antimicrobial and cytolytic polypeptides of amoeboid protozoa-effector molecules of primitive phagocytes. Dev. Comp. Immunol. 23:267-279.

Maurel, P. and P. Douzou. 1976. Catalytic implications of electrostatic potentials: The lytic activity of lysozyme as a model. J. Mol. Biol. 102:253-264.

Muraki, M., M. Morikawa, Y. Jigami, and H. Tanaka. 1988. Engineering of human lysozyme as a polyelectrolyte by the alteration of molecular surface charge. Protein Eng. 2:49-54.

Ó’Fágáin, C., P. M. Cummins, and B. F. O’Connor. 2011. Gelfiltration chromatography. Protein Chromatography. Humana Press pp. 25-33.

Ogundele, M. O. 1998. A novel anti-inflammatory activity of lysozyme: modulation of serum complement activation. Mediat. Inflamm. 7:363-365.

Parry, R. M., R. C. Chandan, and K. M. Shahani. 1965. A rapid and sensitive assay of muramidase. Proceedings of the Society for Experimental Biology and Medicine. Society for Experimental Biology and Medicine (New York, NY). Royal Soc. Med. 119:384-386.

Peeters, T. L., Y. R. Depraetere, and G. R. Vantrappen. 1978. Radioimmunoassay for urinary lysozyme in human serum from leukemic patients. Clin. Chem. 24:2155-2157.

Prager, E. M. and P. Joliès. 1995. Animal lysozymes c and g: an overview in lysozymes: Model enzymes in biochemistry and biology. Birkhäuser Basel. pp. 9-31.

Ranieri, M. L., J. R. Huck, M. Sonnen, D. M. Barbano, and K. J. Boor. 2009. High temperature, short time pasteurization temperatures inversely affect bacterial numbers during refrigerated storage of pasteurized fluid milk. J. Dairy Sci. 92:4823-4832.
Raynal-Ljutovac, K., G. Lagriffoul, P. Paccard, I. Guillet, and Y. Chilliard. 2008. Composition of goat and sheep milk products: An update. Small. Rumin. Res. 79:57-72.

Shoo, N. R., P. Kumar, B. Bhush, T. K. Bhattacharya, A, Sharma, S. Dayal, P. K. Pankaj, and M. Sahoo. 2010. PCR-SSCP of serum lysozyme gene (Exon-III) in riverine buffalo and its association with lysozyme activity and somatic cell count. Asian-Aust. J. Anim. 23:993-999.

Saint-Blancard, J., P. Chuzel, Y. Mathieu, J. Perrot, and P. Jollès. 1970. Influence of $\mathrm{pH}$ and ionic strength on the lysis of Micrococcus lysodeikticus cells by six human and four avian lysozymes. Biochem. Biophys. Acta Enzymol. 220:300-306.

Salton, M. R. and J. M. Ghuysen. 1959. The structure of di- and tetrasaccharides released from cell walls by lysozyme and Streptomyces F1 enzyme and the beta ( 1 to 4$) \mathrm{N}$-acetylhexosaminidase activity of these enzymes. Biochim. Biophys. Acta. Dec. 36:552-554.

Sava, G., A. Benetti, V. Ceschia, and S. Pacor. 1989. Lysozyme and cancer: role of exogenous lysozyme as anticancer agent (review). Anticancer. Res. 9:583.

Su, C. K. and B. H. Chiang. 2006. Partitioning and purification of lysozyme from chicken egg white using aqueous two-phase system. Proc. Biochem. 41:257-263.

Vasstrand, E. N. and H. B. Jensen. 1980. Affinity chromatography of human saliva lysozyme and effect of $\mathrm{pH}$ and ionic strength on lytic activity. Eur. J. Oral Sci. 88:219-228.

Wilken, L. R. and Z. L. Nikolov. 2006. Factors influencing recombinant human lysozyme extraction and cation exchange adsorption. Biotechnol. Progr. 22:745-752.

Xue, Q. G., K. L. Schey, A. K. Volety, F. L. Chu, and J. F. La Peyre. 2004. Purification and characterization of lysozyme from plasma of the eastern oyster (Crassostrea virginica). Comp. Biochem. Physiol. B. Biochem. Mol. Biol. 139:11-25.

Yang, B., J. Wang, B. Tang, Y. Liu, C. Guo, P. Yang, T. Yu, R. Li, J. Zhao, L. Zhang, Y. Dai, and N. Li. 2011. Characterization of bioactive recombinant human lysozyme expressed in milk of cloned transgenic cattle. Plos One 6(3):e17593. 